\title{
Performance-Based Building: Key Concepts, Opportunities, Barriers and Paradigm of Proposed Solution
}

\author{
Serkan Arslan \\ Civil Engineer, M.Sc. \\ Istanbul Technical University, Institute of Science and Technology, \\ Project and Construction Management PhD Program, Istanbul
}

\author{
Alaattin Kanoglu \\ Ph.D., Professor \\ Istanbul Technical University, \\ Faculty of Architecture, Istanbul
}

\begin{abstract}
It is a reality expressed also in the literature that it has become inevitable now for the construction industry, which adopted specific patterns as to the production process until recently arising from various impossibilities as well as for practical reasons within and without the sector, to take into consideration the developing and changing conditions and approach reconstruction works in this sense including the cited changes. In line with this approach, starting point of this study comprises determination of key concepts as competition by design, competitive advantage, interoperability, integration, building information modeling, innovativeness, information technology and performance and the entire process must be rethought with an integrated point of view within the context of "performance-based building". It has been studied on models for measuring performance at various levels in the construction sector for a long time. The most fundamental shortcoming in this area is that much as there is a basic perception for considering these studies as a whole in the process from the preliminary decision stage to the end of the construction stage in construction projects, the main axles belonging to "an approach of making a structure showing system behavior" have not been set forth with an integrated approach at a sufficient level in line with this perception. This study aims to discuss the need for change of the "performance-based building" concept in building production in present conditions even if not for the whole sector- and using it as a tool for putting into practice in the required and eligible projects by trying to basically discuss the elements deemed primary together as far as possible and by getting into details only for necessary points , due to the vast context thereof, and put forward and base on the limited number of concepts listed hereinabove while doing so. As a result of this process, it will be tried to determine the infrastructure requirements, possibilities and existing barriers needed to put the concept to practice and, in the light of these, to define required structures needed for organization structure, information technology and measurement/calculation/evaluation systems at conceptual level.
\end{abstract}

Keywords: Competition, competitive advantage, innovation, interoperability, information systems, performance-based construction.

\section{INTRODUCTION}

"Performance" is a measurable phenomenon. According to what criteria and at what performance level achieving a target is as important as reaching the goal. "How to measure performance" has become one of the main topics discussed as much as "how performance can be increased" by the applying parties, academia and literature in recent years in the building production in addition to many other sectors. There are numerous studies and publications in the literature conducted for models as regards measurement of performance on various levels 
such as operation, activity, project, company, and key performance indicators. These studies are as regards performance of:

- all or certain phases of production processes,

- products produced at the end of the production processes,

- projects meaning the entire product and process as a whole,

- functions within these processes,

- organizations of stakeholders which have to fulfill these functions,

- specific units/departments or the personnel in these organizations, and

- industries which these organizations and projects are a part of.

Some of these studies try to determine the factors affecting the performance of a specific subprocess or the entire production process or try to develop models to measure their effects while there are also studies which try to measure the performance of a product, in other words the building, in terms of certain functions to be fulfilled thereby or the complete performance thereof.

It seems to be a difficult and complicated problem to measure the total performance of a set of production activities (projects) in which such complex structures, processes and relations are involved in an environment where researchers profess that models which measure the performance of a product, process, company, project or industry which are all valid under certain environmental conditions and within limited areas.

The need for studies as to solution of the problem in terms of all levels, stakeholders, functions, phases, entity and facts, in other words how the measurement of performance should be made and models to be produced as a result of these studies is obvious. The measurement of performance, in addition to determining the factors that affect performance in a positive or negative way, is also essential for analytically determination what kind of values have been obtained in which components which constitute the total value of performance and for identifying problematic subfields. The determination of these problematic areas will ensure carrying out efforts to increase performance in a more systematic and targeted manner.

If the building process has been a process consisting of a single phase and in which a single actor had a role in it, then the effective results of the mentioned studies hereinabove could possibly be taken in a shorter time. However, it is observed that the issues at the point reached are still largely unsolvable. Projects cannot be completed within the planned time and budget, the resulting products lose function in a short time, degenerate and require repair and results which are far away from meeting the necessary comfort conditions as regards investors or users and achieving the performance values determined by specifications or standards emerge. Much as a small part of these issues are detected and solved only when they are at design and construction phases, an important part thereof does not emerge until a certain stage phase of operating/use. This issue continues because integrated structures including CRM - Customer Relationships Management approach and tools which will provide feedback of building and operating phases to design, and studies conducted on this issue are new and with a limited number in the industry.

Certain actors undertaking certain functions at each stage of the construction process and not transferring some ideas and concerns in the previous stage to shareholders as needed in the following stages, when these stages are completed in order and it is passed to another stage, causes breakdowns in a multi-phase and multi-stakeholder production process and problems due to incomplete/faulty communication. 
Fragmentation between phases/processes/stakeholders cannot be eliminated in spite of all efforts and developed methods, continues to exist as one of the main obstacles to increase the performance. Much as current information technology offers very powerful tools on this issue, there are still shortcomings in the integration efforts towards solution synthesized by using these tools.

These disconnections also pose significant problems for the expected performance of the product. Performance, has a very subjective nature with its many features and there are difficulties in its being understood and measured by the actors involved in the production in the same way. The parties speaking the same language and understanding the same thing from the things spoken and written is the most fundamental requirement in defining a common evaluation system on which it has been agreed upon by all stakeholders. In practice, it is thought that descriptive specifications are the easiest or the most practical way of providing this in traditional project procurement processes. For this reason, it is essential to determine the expectations of the client from the project in many processes Kamara et. al. [1]. It is also seen that there are various difficulties in adapting the tools, techniques and methods developed for industrial production to the field of building production.

The structure of the building production process may cover alternative routes having important differences as mentioned earlier. Project procurement/delivery systems may cause design and implementation of different process structures which are formed in line with the basic characteristics of the project. From time to time accelerated processes are needed in line with the priorities of the clients as well as importance and effects of various risk factors and one of the sub-processes may begin before the end of the other and sometimes even their location and sequence can become different in a considerable way when compared to the conventional process.

\section{PROBLEM IDENTIFICATION}

Successful completion of construction projects in terms of client's point of view is directly related to the dissemination of competitive advantage concept and its advantages to all stages of the process when increasingly complex, large-volume and complex projects are in question.

Project procurement/delivery systems carried out in competition-based environments allow the client to achieve a price reduction advantage by bringing contractors face to face with each other as to a design product, characteristics of which have already beforehand been described in a full and detailed manner. Much as this approach has an obvious profit for the client together, it becomes invalid especially in projects where time becomes a key factor and construction has to be started before the design is completely finished. Under these circumstances, the project procurement/delivery period often has to be finalized through preliminary design.

On the other hand, instead of reducing the competitive environment to a project specific procurement/delivery process and an application limited to it, extending the same environment to the design process, paves the way to obtain results more appropriate in terms of time, cost and quality objectives of the project based on the competition conditions to be created during this process. In other words, the bidders, instead of seeking solutions within a limited area based on descriptive specifications, will begin to design various components of the products with newer/faster technologies, with better quality and in a more durable, longer lasting and more economical way. 
When the issue is examined more profoundly, it will be understood that this approach, which appears to be a reasonable proposal at first glance has significant difficulties in implementing. First and foremost, since the bidders will not offer bids for the same unique product unlike the traditional approach, it is impossible to make an easy and quick comparison on the basis of product and price. Furthermore, it is a known fact that stakeholders avoid complex and uncertain processes in a process where time is very valuable.

It is obligatory to reveal the expectations of the entrepreneur as to the product with an approach based on the definition of product performance and having flexibility in inputs and technologies as to product and production process instead of using descriptive methods and approaches based on the definition of physical attributes, such as product dimension/density etc., which conflicts with its objective of carrying the competition environment to design process. The infrastructure required for organizational structures, staff qualifications, creation and organization of the required unified data, their submission to usage and, etc. in design and project delivery process of this approach to which the sector is not very accustomed also does not exist.

All processes and components of a performance-based evaluation method must be defined for comparison of the proposals submitted and all shareholders in the competitive environment must have an access to it. Thus, while design decisions are being taken, their effects on consequences and performance will be known simultaneously by designers and related shareholders. Furthermore, as a result of evaluation, each shareholder will be able to monitor transparently all elements which affect the result analytically. However, unified and interoperable conceptual models, integrating design and project procurement processes in terms of information technology and objective superstructure/practical tools and new software models which have to be designed accordingly and which are needed to realize this approach are not yet fully available.

An approach to be proposed as alternative to the traditional approach has to propose processes which will not be weak compared to the advantages of familiarity to established and customary processes in the implementation of the traditional method and which are fast, practical and easy-to-implement and use technological opportunities to support them. Integrated software solutions also are not available in this subject yet.

Today when relative importance of time has increased very much, abandonment of project procurement/delivery approaches realized in a competitive environment which requires fully completion of design documents and determination of contractors through negotiations lead to delivery of projects to the contractors with methods like cost plus fee in which total construction cost is not known in advance and through organizational approaches such as design-build integration and losing a significant advantage provided by the competitive environment to the client.

On the other hand, clients who do not wait the design to finish completely and who do not give up project delivery process based on competition, try the way of realization of the tender with preliminary design documents in many cases and this occurrence leads to participation of contractors in tenders with incomplete information due to inability to create a well prepared specification in adequate level and this causes significant disagreements and conflicts to arise between the parties. Resolution of these conflicts causes loss of time and resources while the objectives of the project become distant and losses in performance of the project are experienced as unavoidable consequence of this. 
The necessary condition of leaving the traditional approach, extending the competition to the whole process and achieving the profits thereof is increasing the integration efforts to be realized between the phases of the building production process. In this regard, organizational models appropriate for the structure of design- building approach have begun to take place in application. However, the infrastructure to support this approach is insufficient as mentioned hereinabove.

The problem, briefly, is the continuity of inadequate and unqualified product arising from the basic characteristics of the traditional building production process and the presence of the production process incident thereto. Approaches which will make the competition environment not only applicable in the project procurement process but which will extend it also to the design process and which will obtain the profit of it by imposing design/construction companies to find innovative solutions and products and integrated processes based on new and advanced technologies suggested by this solution and which will increase the performance as to time, money and economic objectives of the project in terms of the customer are needed in order to solve this problem. However, there is no infrastructure required at the relevant sector and company levels as to organizational and information technology to realize these approaches.

\section{TARGET, OBJECTIVES AND METHODOLOGY OF THE STUDY}

It is aimed to define the conceptual structure of an integrated model, components thereof and relations between them for solving the problem described hereinabove, and subsequently develop a practical software model for the purpose of application in line with this conceptual structure at practical dimension within the context of this study. To this end, the target to be achieved within the context of a range of researches as well as objectives and methods in question to reach this target are described below:

- Development of a conceptual model for measuring product performance with a consistent method as to at which levels the performance of the product and the components thereof can be measured and scored.

- Development of a conceptual model for measuring process performance with a consistent method as to at which levels the performance of the process and the components/actors thereof can be measured and scored.

- Having the possibility of designing a measuring/evaluation model incident to both phenomena in an integrated structure in development of an integrated measuring/calculation/evaluation system which will allow conducting the measurements of performance of the product and process on the same platform.

- Ensuring the development of model in line with the criteria to be obtained by discussing the works made for proving the validity of the developed conceptual model in academic and professional platforms.

- Development of a software model integrating design and project supply/delivery processes and allowing the identification of the requests of the clients, their objectives and expectations as regards the project and the significance they attribute to them with the value system before the design and forwarding thereof to the design group and subsequently evaluating the submitted offers basing on the same value system in a performance-based manner and selecting the appropriate offer.

- Getting in touch with various companies for proving the validity of the developed conceptual model and transferring into practice and examination of administrative and bureaucratic processes.

- Identification of barriers as to legal legislation and proposing of steps as regards the relevant legislation in another dimension of transferring the model to practice. 
This study aims to introduce the modules constituting the backbone of a model comprising the entirety of components listed hereinabove to be put forward by studies to be carried out within the context of doctoral thesis or research projects conducted simultaneously by teams each of which is separate than the other but in relation with the other.

\section{PERFORMANCE-BASED BUILDING (PBB): KEYWORDS}

While performance-based production approach supports innovative solutions, it allows making estimate not just on cost and time but also value estimate as regards quality. However, project delivery systems comprising a performance-based approach should be supported in various dimensions with appropriate structures. Integrated models, to be used also in the field of professional practice in addition to their usage in the lack of all integrated approach on the conceptual scale, will ensure widespread utilization of innovation in the construction industry. The present system causes contractors to submit cheap and poor quality building proposals or in other words producing cheap and poor quality buildings are rewarded. The main factors for solution, as indicated in Figure 1, which include extending the competition to the entire building production process and in particular to the design process, innovativeness, solutions interoperable with IT support as well as integrated solutions and performance-based evaluation should be taken as a whole and it should be ensured that this approach is utilized in a widespread manner in the construction industry.

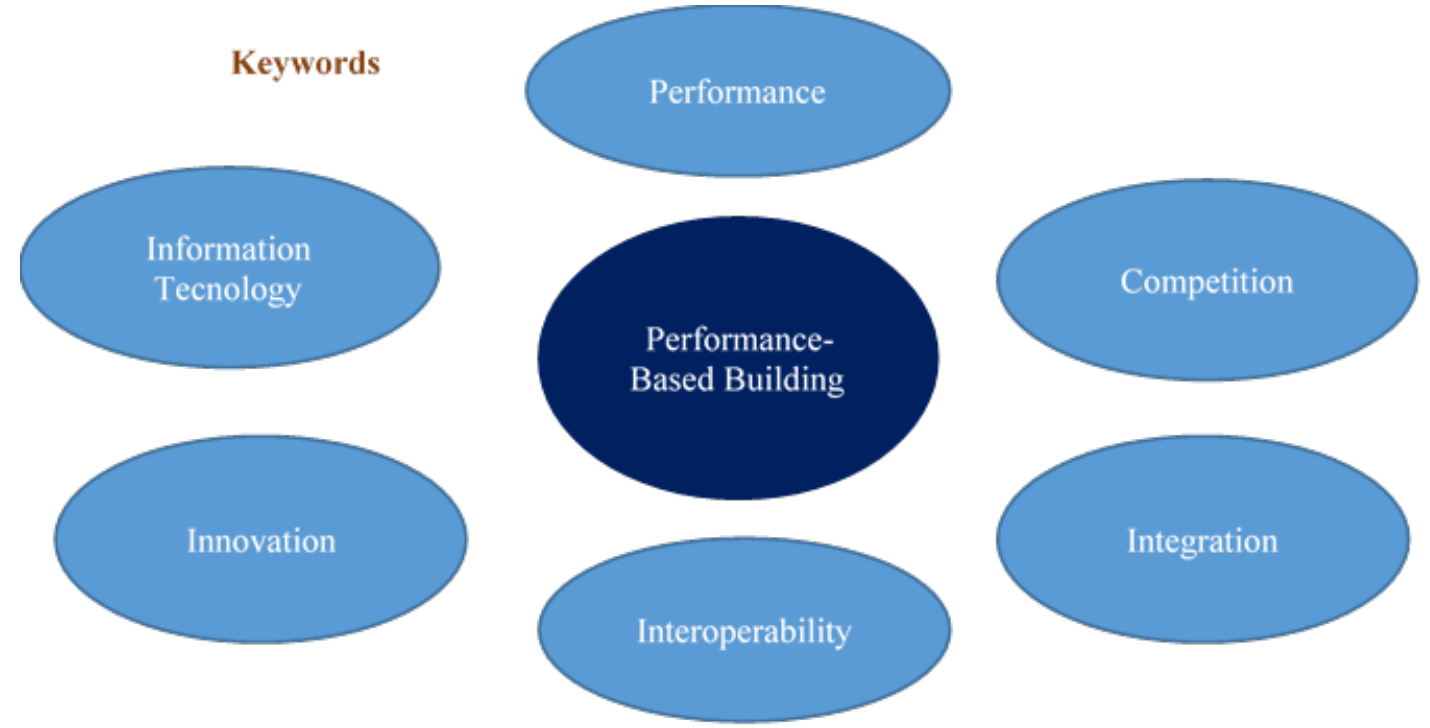

Figure 1. Key words to be considered in the design of the paradigmatic model

\section{Innovation Concept: Encouragement of Innovation in Design and Construction}

Performance-Based Building - PBB approach defines 'what the subject should exist as' and 'how that subject is needed' rather than describing how to manufacture a building or material in descriptive texts Hattis [2]. PBB approach, in the broadest sense, is a result-oriented thinking and working application. In this approach, the aim is to regulate the requirements of the client, the end user, the standards and the regulations on material, system and component basis and in a way that the construction method meets the needs of the building.

The concept of PBB has become quite widespread in recent years and has continued to expand with increasing momentum by being intertwined with laws, regulations and regulations based on this concept Fairclough [3]. One of the most important reasons of interest to this concept is the view that traditional approaches of our day, makes a barrier effect in front of the innovative approaches and that this barrier will continue in this way as long as it is not stopped or controlled by descriptive laws and regulations Foliente [4]. 
Much as performance-based approach has numerous benefits arising from the definition thereof, these benefits are not enough for widespread use of the approach in the industry. It is necessary to identify the obstacles causing this and eliminate them. What is aimed with the PBB approach is to increase the quality of buildings to higher levels. And the success for increasing the quality of buildings to higher levels performance depends on not in using a dictating/compulsive way for PBB approach by descriptive specifications but by defining the performance criteria of the product and by acting in an open way to innovative solutions which will achieve realization of those criteria.

Similarly, Bowen and Thomas [5] have underlined the fact that to obtain the necessary performance, laws legislations and regulations intended for performance have to allow achieving the freedom to choose, flexibility and innovation among various alternatives. Likewise, according to Fairclough [3] performance-based production approach which is successful in the UK can survive with thanks to some accepted documents. These documents are PBB guidelines and their difference from the descriptive specifications is that they are open to innovation. However, Baark [6] has reminded that this approach towards innovation in the construction industry at the same time contains some risks; unknown issues innovations enter the industry with every innovative technology; approval of all new systems have to be obtained; implementer companies report excuses for not using products or systems which they do not know and innovations sometimes are considered to be unnecessary or redundant. Of course, the most important factors which underlies these risks are financial and time related concerns. These opposing views have led to formation of some preconditions for the PBB approach, which, according to those who advocate the approach, are completely unnecessary.

Innovation is defined as the effective renewal of the features of the present generation and putting this new idea into practice, in order to enhance organizational performance as a whole through successful innovation Barrett and Sexton [7]. Researchers claim that the prerequisite of foreseeing and improving the potential benefits of performance-based production must not be related simply to innovation activity superficially but rather it can be achieved by incorporating the applications of this approach into business logic of the innovation activity and organizational management. Briefly, if PBB is desired to be a widely preferred and selfmotivating action in the construction industry, the advantages and benefits of the said approach for the sector should be clearly stated. Ambiguity, uncertainty and risks in applicability of technologies and systems which incorporate innovation are the obstacles to PBB approach.

\section{Competition Concept: Diffusion of Competition through Building Production Process}

One of the most important obstacles in the construction sector is that the client, especially the public- sector client, chooses low quality. Constructors, planning to do work with high quality in project proposals and building constructions, have become disappointed when they are compared to bidders offering lower prices for the same work or constructing lower quality buildings and because proposals of the second group are often preferred Minchin and Smith [8].

Competition in the construction industry is one of the most important factors for increasing the quality of the both bidding process and the product. However, competitive bidding processes alone are not enough to achieve quality. Another important factor is the consistency in the context of the bidirectional information flow between the procurement and construction processes. The architectural and engineering offices must determine and understand customer needs and expectations and transform them into specs throughout the project and a common 
and appropriate solution must be found in this way. Otherwise, design changes in subsequent processes will cause re-works, delays and extra costs.

Traditional Design/Procurement/Construction process, requires transition to tender phase after detailed design and quality plans are ready. This system is a tender system in which companies prepare their bids for the same product which are compared with each other and the single variant is the bid price. The employers consider that this system has the ability to respond to the request thereof in the best way inasmuch as all details of the project are determined. However, the issue which has not to be ignored in this method is the fact that competition is limited only to the project procurement phase and it is not extend to other processes.

The construction industry is directed through two main factors: competition and achievement. General understanding in the industry is that stronger competition can be achieved by lowprice and high performance is always more expensive. Kashiwagi [9], in his study, has tried to define the construction industry with a diagram consisting of four groups basing on competition and performance parameters.

\section{Integration Concept: Integration of Production Processes via BIM, Interoperability and Information Technology}

The concept of integration is one of the most important key words considering the fragmented structure of construction industry. The losses of the sector are in important dimensions both due to the multi-phase structure thereof and the fragmented structure of these phases due to lack of communication between the stakeholders and its being with multi-stakeholders. For this reason, any recommended approach should have also an answer to this problem. In addition to organizational integration solutions like design-building, the support of information technology is also essential for models to be proposed in this area. Therefore, it should be ensured that information classification systematics for integrating, approaches as to building information modeling and all practical integration tools expressed with conceptual and 4D, 5D, 6D extensions, and the models to be created with these tools must be included in the required place within this plan.

It is possible to approach the issue from many different directions and intersections and in addition to the presence of integration models addressing the entire construction processes such as the models reported by Kanoglu and Arditi [10], there are also studies trying to integrate design and construction processes like the models reported by Alptekin and Kanoglu [11], and those trying to integrate design and business processes such as the models reported by Ercoskun and Kanoglu [12], Yazicioglu and Kanoglu [13, 14, 15, 16, 17, 18], Altindag and Kanoglu [19]. Similarly, this study has a perspective which integrates design and project procurement processes.

Thus, communication problems both between the phases of the process and the various stakeholders involved in these phases will be eliminated while validity, continuity, consistency and transparency of the decisions taken by the entrepreneur/investor/owner/administration as well as parameters, weights and value system which are essential for the project will be ensured during the project procurement process. The fundamental and essential element of this subject is to ensure uniformity in information classification and coding systems such as Uniformat, Masterformat, OmniClass and etc. and "interoperability" which must be supported by Building Information Modeling (BIM) works and which ensures communication between object-oriented design software 


\section{Basic Dimensions as Regards Solution}

It has been concluded, as a result of the examinations made, the model which will be developed for the solution of the identified problem must include and reveal the components of the solution in the following dimensions:

1. Philosophical/Paradigmatic Model: Proposal of a new approach, understanding and mode of production to the construction sector of the study and the model to be produced is the cited target within this context.

2. Process-Related/Organizational Model: The definition of organizational entities, relations, rights, authorities and responsibilities which will be covered through the study and the model to be produced is the cited target within this context.

3. Integration/Interoperability Model: Identification of integration processes between various stages of production within the context of the study and the model to be produced is the cited target within this context.

4. Computational/Evaluation Model: Determination of design and production performance parameters and performance criteria and development of a performance evaluation system for the project procurement/delivery process within the context of the study and the model to be produced is the cited target within this context.

5. Computer/Software Model: Identification of processes, modules and components for automation software and reporting system is the cited target within this context.

It can be said, in the light of this evaluation, that it has become inevitable to discuss again the building production process and the functions and relations of the shareholders involved in this process and put into practice a paradigm supported by project procurement processes basing on a performance based evaluation by virtue of tools including also current information technology (Figure 2). 


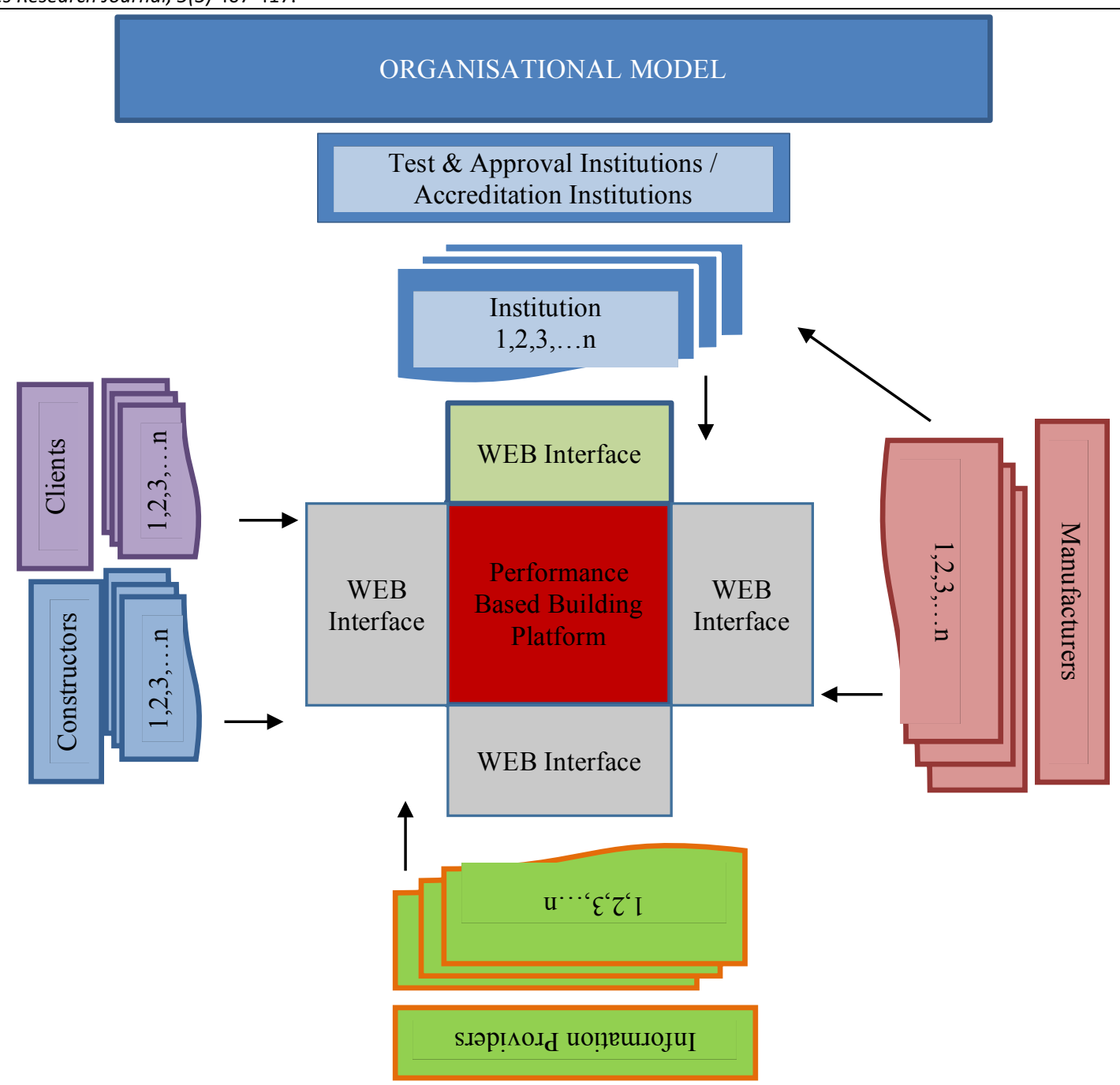

Figure 2. Rearrangement of the relations of the shareholders involved in the organizational model through the web interfaces and building production process

\section{CONCLUSIONS}

It was tried to identify the barriers preventing the development and production of an integrated model required by entrepreneurs/clients/owners in the construction sector to fulfill their project delivery/procurement functions in addition to possibilities and key concepts constituting the paradigm related to solution in this study.In order that a performance-based approach can be applied in a significant part of the industry as a valid and effective approach depends on conducting sufficient level of studies include all the necessary dimensions for examination of all its aspects in a sufficient level and transferring to application. An extremely comprehensive and long-term work needs to be carried out within the context of sub-projects which are identified within a master project and each of which is operated in coordination. Numerous subprojects planned for this purpose, some of which have been completed and some of which are still being carried out, have been carried out by a large number of researchers.

\section{References}

Kamara, J.M., Anumba, C.J., ve Evbuowman, N.F.O., (2002). Capturing Client Requirements in Construction Projects, Thomas Telford, Cornwall.

Hattis, D., (1996). "Role and Significance of Human Requirements and Architecture in Application of the Performance Concept in Building”, Proceedings of the 3rd CIB-ASTM-ISO- RILEM International Symposium, NBRI, Haifa, Israel. 
Fairclough, J., (2002). Rethinking Construction Innovation and Research: A Review of Government R\&D Policies and Practices, Department of Trade and Industry/ Department of Transport, Local Government, Regions, London.

Foliente, G.C. (2000). "Developments in Performance-Based Building Codes and Standards”, Forest Products Journal, Vol.50, No.7/8, 12-21.

Bowen, R., and Thomas, R. (1997). TG11 - Performance-Based Building Codes. CIB Report 211, CIB, Rotterdam.

Baark, E., (2001). “The Dynamics of Innovation in Engineering Consultancy Services”, in Proceedings of the Future of Innovation Studies conference, Eindhoven, the Netherlands, 20-23 September.

Barrett, P., and Sexton, M.G., (1998). Integrating to Innovate. Report for the Construction Industry Council, DETR/CIC, London.

Minchin, R.E., and Smith, G.R., (2005). “Quality-Based Contractor Rating Model for Qualification and Bidding Purposes", Journal of Management in Engineering, Vol. 21, No. 1, 38-43.

Kashiwagi, D.T., (1999). The Construction Delivery System of the Information Age, Automation in Construction, Vol. 8, 417-425.

Kanoglu, A., and Arditi, D., (2004). "An Integrated Automation System for Design/Build Organizations", International Journal of Computer Applications in Technology, Indersience Publishers, Vol. 20, No. 1-3, 3-14.

Alptekin, G.O., and Kanoglu, A., (2003).“A Computer-Based Feedback Model for Design/Build Organizations”, ISEC02 - 2nd International Structural Engineering and Construction Conference, Organized by University of Rome, Italy, 23-26 September, 2221-26.

Ercoskun, K., and Kanoglu, A., (2003).“Customer Relationships Management in AEC Sector”, 20th International Conference on Information Technology for Construction, Organized by CIB W78 Auckland, New Zealand, 17-19 April, 129-136.

Yazicioglu, D.A., and Kanoglu, A., (2015) "Enhancement of the Designer Performance in Kitchen Interior Design", Advances in Social Sciences Research Journal, Vol. 2, No. 6, 1-8.

Yazicioglu, D.A., and Kanoglu, A., (2016) “Determining Effects of Kitchen Design Rules on Kitchen Functionality in A Comparative Way", Academic Research International, Vol. 7, No. 3, 25-44.

Yazicioglu, D.A., and Kanoglu, A., (2016) "A Systematic Approach for Increasing the Success of Kitchen Interior Design within the Context of Spatial User Requirements", Advances in Social Sciences Research Journal, Vol. 3, No. $1,155-166$.

Yazicioglu, D.A., and Kanoglu, A., (2016) "Improving the Project Service Performance of Companies Producing and Marketing Kitchen Systems to Provide Sectoral Competitiveness", International Journal of Sciences: Basic and Applied Research, Vol. 26, No. 2, 18-27.

Yazicioglu, D.A., and Kanoglu, A., (2016) "Performance-Based Automation System for Kitchen Interior Design", Advances in Social Sciences Research Journal, Vol.3, No.13, 27-45

Yazicioglu, D.A., and Kanoglu, A., (2017) "Improving the Project Service Performance of Companies Producing and Marketing Kitchen Systems: Stage of Survey and Analysis of the Space”, International Journal of Advanced and Applied Sciences, Vol.4, No. 2., 139-146.

Altındağ, M., and Kanoglu, A., (2016) Yüklenici Firmaların Proje Temin Birimleri İçin Başarım Tabanlı Bir Ölçme ve Değerlendirme Modeli Önerisi, Anadolu Üniversitesi, 4. Proje ve Yapım Yönetimi Kongresi, Eskişehir, 3-5 Kasım. 